\title{
Using aerial drones to select sample depths in pit lakes
}

\author{
DN Castendyk Golder Associates Inc., USA \\ BJ Straight Golder Associates Inc., USA \\ JC Voorhis Golder Associates Inc., USA \\ MK Somogyi Golder Associates Inc., USA \\ WE Jepson Montana Department of Environmental Quality, USA \\ BL Kucera Thompson Creek Mining Company, USA
}

\begin{abstract}
Regulators often require mining companies to monitor the water quality of pit lakes during closure. Aerial drones, or unmanned aerial vehicles (UAVs), are poised to revolutionise pit lake monitoring and management by: (i) reducing risks associated with water sampling, (ii) lowering costs associated with sampling, and (iii) increasing the frequency of data acquisition. This paper demonstrates how in situ profiles of temperature and specific conductance collected by aerial drones in advance of water sampling can be used to select optimal sampling depths and to inform samplers of the physical state of the pit lake. We provide case studies of drone water sampling at two pit lakes located $295 \mathrm{~km}$ apart in the northwest United States. These pit lakes have similar maximum depths, latitudes, and surface elevations, and both require drone water sampling. The Montana Tunnels Pit Lake near Jefferson City, Montana is inaccessible to both foot and vehicle traffic due to previous pit wall failures. The Thompson Creek Pit Lake near Clayton, Idaho has unstable pit walls that as recently as 2016 generated a large landslide that entered the pit lake and produced a tsunami. The health and safety risks associated with future tsunamis have suspended boat-based water sampling. Both pit lakes were sampled during a three-week period in autumn 2018 when most temperate-zone lakes in North America undergo complete top-to-bottom circulation, called 'turnover'. The aerial drone first suspended a conductivity-temperature-depth (CTD) probe capable of measuring in situ parameters to a depth of $100 \mathrm{~m}$, and then suspended a water sampling device capable of collecting $2 \mathrm{~L}$ water samples up to $120 \mathrm{~m}$ deep. On 23 October 2018, in situ profiles collected in the Montana Tunnels Pit Lake showed that complete turnover had occurred and informed samplers that a minimum number of water samples would be sufficient to characterise the geochemistry of the water column. The sampling team collected three water samples from 0,28 and $56 \mathrm{~m}$ depths, and subsequent lab results confirmed homogeneous conditions. State and federal regulators observed the sampling event and accepted the water samples for compliance purposes. In contrast, on 13 November at the Thompson Creek Pit Lake, in situ profiles indicated variable water chemistry with depth and the persistence of summer stratification. As a result of this complexity, samplers collected eight water samples from 3, 8, 15, 17, 36, 40, 55, and 83 m depths. In both studies, the aerial drone methods presented herein provided pit lake managers with important information about pit lake behaviour and water quality which could not have been obtained with boat-based methods owing to access and health and safety risks. These studies highlight the potential for future aerial drone water sampling applications during closure.
\end{abstract}

Keywords: mine void lakes, UAV, UAS, Montana Tunnels Mine, Thompson Creek Mine

\section{Introduction}

Mine pit lakes, or void lakes, are a common feature of active and closed surface mines (Castendyk \& Eary 2009; McCullough 2011; Geller et al. 2013). For pits that extend below the pre-mining water table, pit lakes fill with groundwater, surface runoff, and direct rainwater following a halt in dewatering. Pit lake water quality may degrade by the weathering of wall rock (especially in sulphide deposits), the addition of 
groundwater, and evapo-concentration. Appropriate management of pit lake water quality can prevent costly treatments during closure and potential liabilities during post-closure. Therefore, predicting and monitoring water quality is an environmental priority for managers throughout the mine lifecycle:

- During planning and permitting, numerical predictions of pit lake chemistry are generated using geochemical and hydrogeologic inputs.

- During operations, young pit lakes are monitored, their chemistry is compared against predictions, and models are revised.

- During closure, pit lakes are monitored frequently and treated if necessary.

- During post-closure, less frequent monitoring occurs to assure water quality criteria are met.

Water chemistry may be influenced by seasonal variability in evaporation, rainfall, and runoff - specifically spring freshet (significant in high-latitude mines that accumulate snow during winter) - and spring and autumn vertical mixing events, called 'turnover'. For this reason, sampling pit lakes at a low temporal frequency (i.e. $\leq 1$ event p.a.) can lead to overestimation or underestimation of average concentrations, an inability to track water quality trends over time, and ultimately higher water management and treatment costs. Therefore, monitoring during operations, closure, and post-closure periods should involve sample collection from multiple depths, several times per annum, in order to define temporal and vertical variability in-pit lake water quality.

In temperate climates, pit lakes tend to vertically stratify into chemically distinct layers during summer and winter months. Thermal stratification occurs when sunlight warms surface water, resulting in a shallow layer (the epilimnion) with a lower density and a higher buoyancy than the deep layer (the hypolimnion) (Wetzel 2001). Additionally, chemical stratification may result from the hypolimnion receiving saline groundwater input which increases water density relative to surface water, the addition of suspended particulate matter from the shallow layer, or the depletion of oxygen by organic decay. In 'holomictic' pit lakes, complete turnover occurs annually during the spring and/or autumn, producing a homogeneous water column. In 'meromictic' pit lakes, turnover is incomplete and only mixes the top portion of the lake, leaving a chemically distinct bottom layer (the monimolimnion), typically characterised by high total dissolved solids (TDS) concentrations and reducing redox conditions (Schultze et al. 2017). Due to the possibility of stratification, surface samples may provide a poor indication of overall water quality. Therefore, pit lakes should be sampled at multiple depths in order to capture vertical differences in water chemistry. In the United States, regulators in the State of Nevada require that pit lakes with maximum depths greater than $8 \mathrm{~m}$ are sampled at a minimum of three depths: shallow, middle, and deep (Newman et al. 2018).

One challenge with pit lake water sampling is deciding how many samples to collect and from what depths. In the absence of information on stratification, samples should be collected at a constant sample interval (e.g. $5 \mathrm{~m}$ ) through the entire water column, and the number of samples is based on the maximum depth divided by the sample interval. This approach, while conservative, may result in multiple samples from a homogeneous layer, plus high sampling and analytical costs. It could also completely miss a thin, chemically distinct layer.

Another, critical challenge with pit lake water sampling is safety. Working on or near water is a high-risk activity. Water samplers risk drowning, hypothermia, exposure to chemicals in pit water, and asphyxiation from degassing (i.e. $\mathrm{CO}_{2}, \mathrm{H}_{2} \mathrm{~S}$ ). To access the water surface, workers may encounter unstable ground, such as on unmaintained haul roads, and be working above or below highwalls. At the Berkeley Pit in Montana, USA, an unmanned sample boat was destroyed by a tsunami generated by the collapse of a pit wall (Castendyk et al. 2018). The risk of a boat being capsized by similar pit wall failure suspended water sampling from 2012 to 2017. In the event of an emergency, highwall-shielding of radio and cellular communications, and difficult access for emergency response teams make rescue difficult. Consequently, some pit lakes are deemed 'inaccessible' for safety reasons and are not sampled. This places mine managers 'in the dark' relative to water quality, presenting substantial management challenges and creating significant environmental risks. 
Aerial drone water sampling resolves both problems. Multiparameter probes suspended from drones provide a means to profile in situ physiochemical parameters and field interpretation of these profiles allow pilots to target appropriate, defensible sample depths. Drone aircraft eliminate safety risks associated with working on or near water (Figure 1). Additionally, unlike drone boats, drone aircraft eliminate safety risks associated with pit lake access. In North America and Australia, aerial drones have already been used to sample over 17 pit lakes (Castendyk et al. 2018).

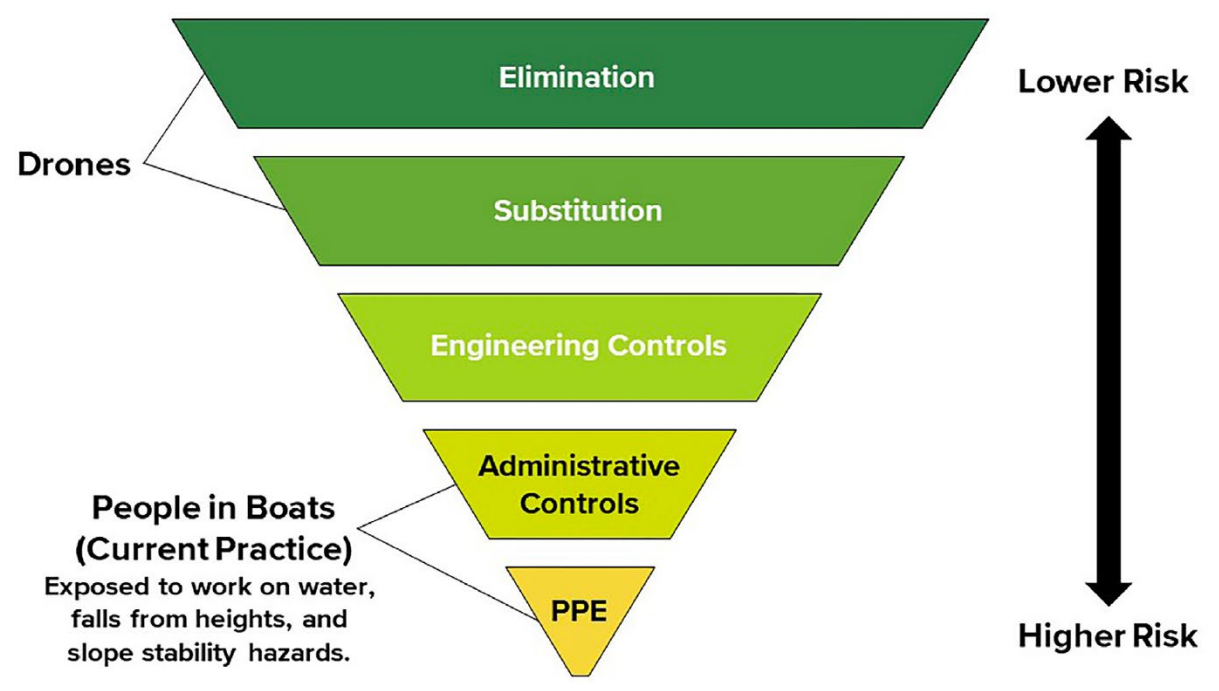

Figure 1 Hierarchy of risk control options for pit lake sampling showing the 'elimination' of work on water as the most effective risk control option, and work on water with staff wearing personal protective equipment (PPE) as the least effective control option. Aerial drones produce low risk through elimination whereas the status quo practice of boat-based sampling creates high risk

The purpose of this paper is to demonstrate how drone-collected in situ profiles of physiochemical parameters guide the selection of sample depths and the appropriate number of samples. We present the instrumentation and methods used for aerial drone water sampling and provide case studies of two pit lakes in the Northern Rocky Mountains of the United States (Figure 2). These lakes were sampled within three weeks of one another in the autumn of 2018. Despite being only $295 \mathrm{~km}$ apart and having similar latitude, elevation, and maximum depth (Table 1), the vertical structure of each lake was unique and required different sampling depths. In both cases, aerial drone water sampling led to a better understanding of water quality and improved pit lake management.

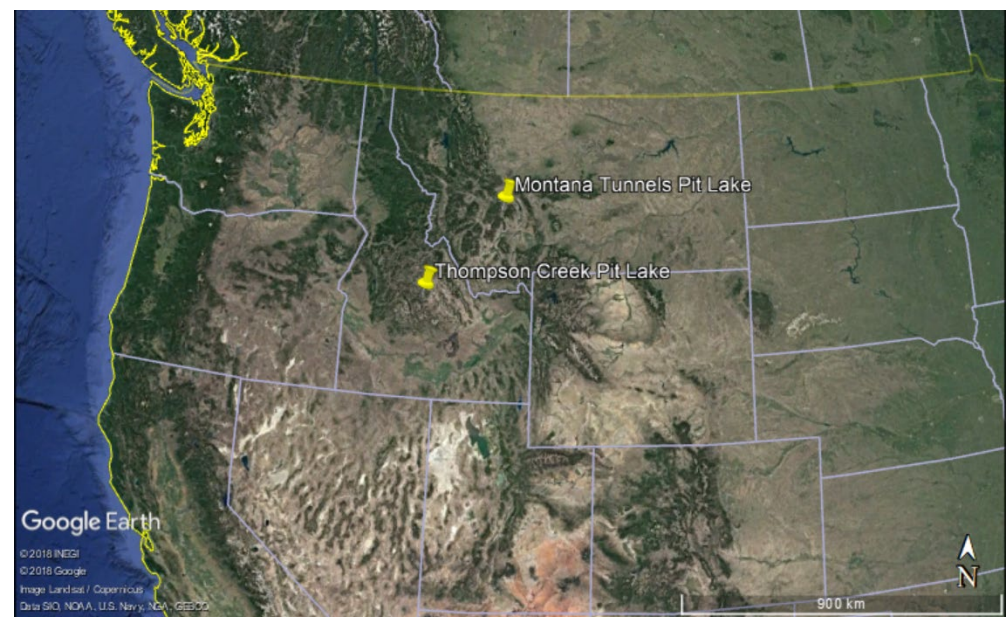

Figure 2 Map of the Northwest United States of America showing locations of the Montana Tunnels and Thompson Creek pit lakes 
Table $1 \quad$ Pit lake characteristics

\begin{tabular}{llcccl}
\hline Name of pit lake & Nearest town & Latitude & Elevation & Max. depth & Sample date \\
\hline Montana Tunnels & Jefferson City, Montana & $46.4^{\circ} \mathrm{N}$ & $1,624 \mathrm{~m}$ & $70 \mathrm{~m}$ & 23 October 2018 \\
Thompson Creek & Clayton, Idaho & $44.3^{\circ} \mathrm{N}$ & $2,010 \mathrm{~m}$ & $92 \mathrm{~m}$ & 13 November 2018 \\
\hline
\end{tabular}

\section{Instrumentation}

Aerial drone water sampling has been made possible by recent advances in both aerial drone technology and multiparameter water monitoring equipment. In 2016, the Chinese aerial drone manufacturer DJI (Da-Jiang Innovations) released the Matrice 600, a six-rotor, or hexa-copter, drone aircraft for approximately USD 4,500 (Figure 3). With the ability to lift a payload of approximately $6 \mathrm{~kg}$, this high-lift-capacity drone has made it affordable to transport equipment other than cameras below aerial drones, such as water sampling devices capable of collecting $2 \mathrm{~L}$-volume samples. This make and model aerial drone is used by at least three drone water sampling service providers in North America.

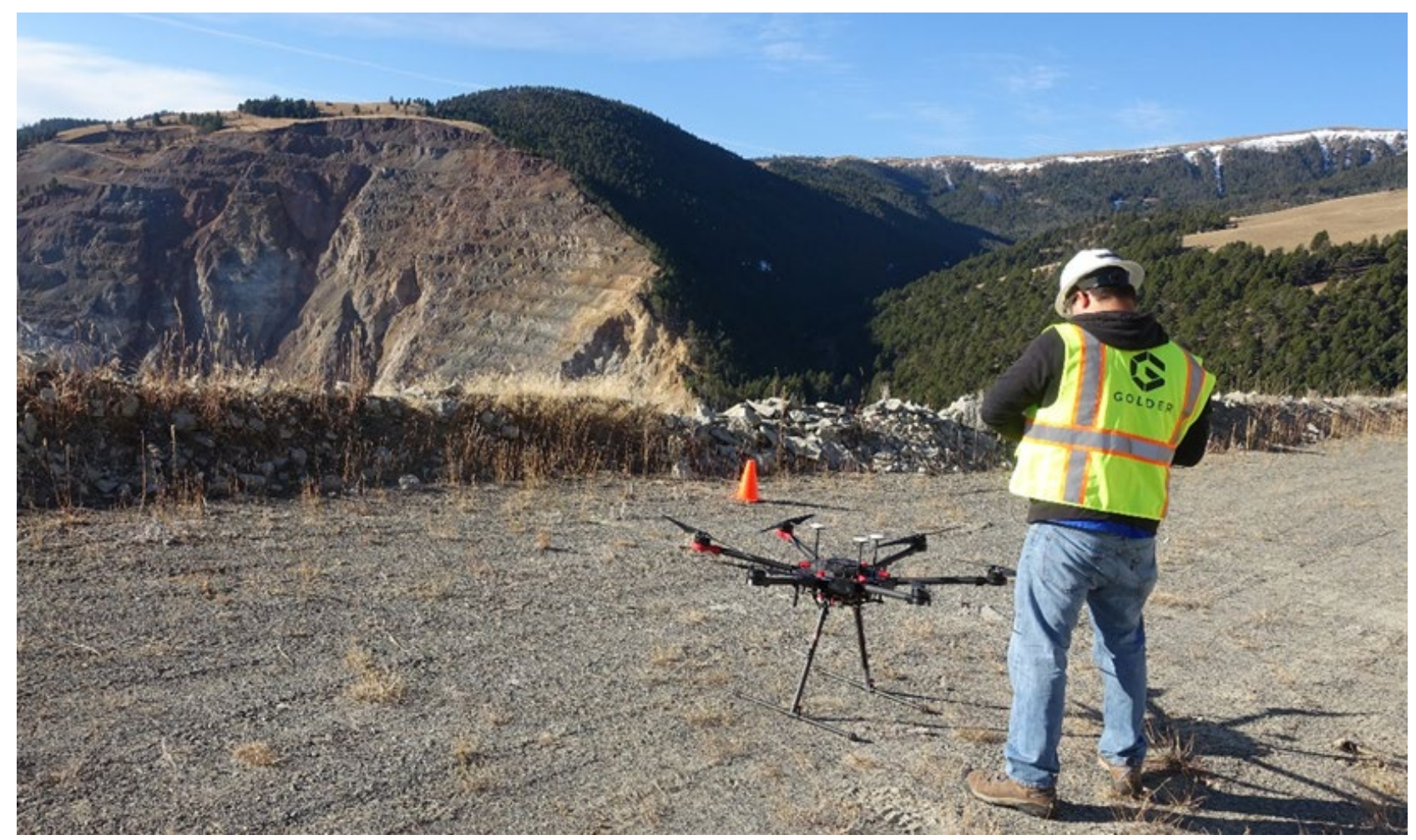

Figure 3 The DJI Matrice 600 drone during a pre-flight check at the Montana Tunnels Pit Lake

Over the past decade, multiparameter probes have become smaller, lighter, and more rugged, serendipitously resulting in equipment that is well-suited for aerial drone deployment. One example is the YSI (Yellow Springs Instrument) CastAway, a conductivity-temperature-depth (CTD) probe which measures in situ temperature and electrical conductivity to depths down to $100 \mathrm{~m}$ (Figure 4). The device calculates water density from temperature and electrical conductivity. This CTD weighs $0.45 \mathrm{~kg}$ and measures parameters at five times per second during its decent and ascent through the water column (https://www.sontek.com/castaway-ctd). Upon retrieval, the CTD rapidly transfers data to a laptop computer via Bluetooth connection, and the companion software graphically displays profiles of in situ parameters which can be used to select sample depths. The CastAway costs approximately USD 6,500. 


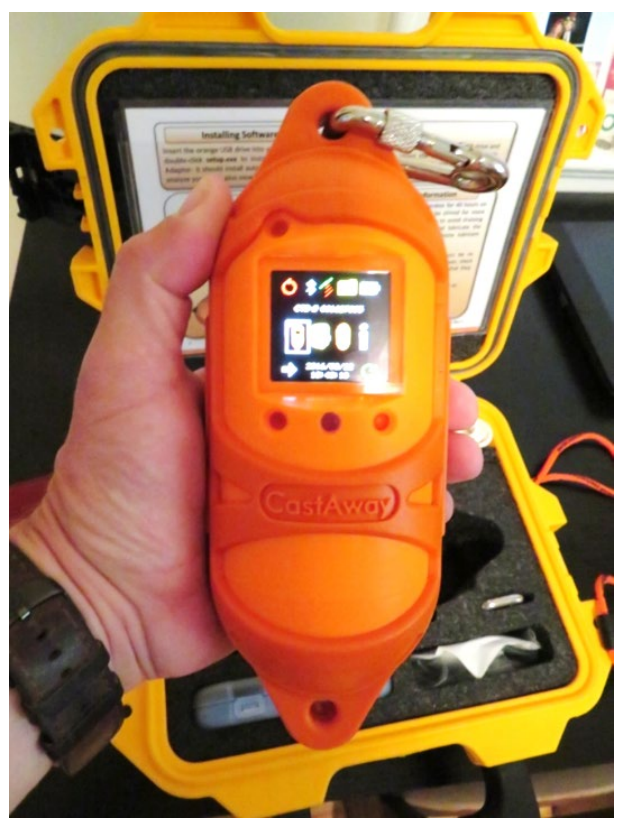

Figure 4 The YSI CastAway-CTD (conductivity-temperature-depth) probe

Another useful tool is the Van Essen Micro-Diver DI610 pressure transducer, which is only $8.8 \mathrm{~cm}$ long and weighs $45 \mathrm{~g}$ (https://www.vanessen.com/products/water-level/micro-diver). This device can record the depth of the sample device to an accuracy of $\pm 10 \mathrm{~cm}$ at a depth of $100 \mathrm{~m}$, and is used to independently verify and correct the depth that water samples are collected.

The final tool is the water sampling device. Table 2 provides a list of published water sampling devices that have been successfully deployed from aerial drones. The reader is directed to these references for further details. The sampling device used in the case studies presented herein collects a $2 \mathrm{~L}$ sample volume, but is proprietary and not described herein.

Table 2 Water sampling devices used with aerial drones

\begin{tabular}{lccl}
\hline Reference & Sample volume & Depth & Description \\
\hline Ore et al. (2015) & $20 \mathrm{~mL}$ & $<1 \mathrm{~m}$ & $1 \mathrm{~m}$-long tube with on-board pump \\
Cornell et al. (2016) & $50 \mathrm{~mL}$ & $0 \mathrm{~m}$ & Falcon tube dipped below surface \\
Koporan et al. (2018) & $130 \mathrm{~mL}$ & $0.6-0.8 \mathrm{~m}$ & Thief-style, messenger-triggered bottle \\
Terada et al. (2018) & $250 \mathrm{~mL}$ & $<0.8 \mathrm{~m}$ & Sample tube with check-valve \\
Washburn et al. (2018) & $500 \mathrm{~mL}$ & $5 \mathrm{~m}$ & Bottle closes at a specific pressure \\
IRYS Pty Ltd (2016) & $1,000 \mathrm{~mL}$ & $0 \mathrm{~m}$ & Thin tray submerged in water \\
Castendyk et al. (2017) & $1,250 \mathrm{~mL}$ & $80 \mathrm{~m}$ & Niskin sample bottle \\
Williams et al. (2018) & $2,000 \mathrm{~mL}$ & $83 \mathrm{~m}$ & Proprietary sampling device \\
\hline
\end{tabular}

\section{Procedure}

Aerial drone water sampling is performed by a two-person sampling team consisting of a pilot and a spotter. The pilot is responsible for flying the drone, defining a 'safe flight area', and ensuring equipment is operating properly. The spotter is responsible for ensuring no one enters the 'safe flight area' during operations, watching for changes in environmental conditions (i.e. weather, birds, vehicle traffic), assisting the pilot to position the drone over the sample point, managing spectators, and collecting the water sample device when 
the drone returns. Typically, the sampling team is accompanied by a client representative who assumes Chain-of-Custody once water samples are collected.

The following drone sampling procedure is used:

1. Upon arrival at site, sampling team reviews weather conditions and decides whether sampling is possible. Moderate to strong winds can push the drone away from the study area and precipitation and condensation can damage exposed circuitry. At many lakes, wind speeds tend to increase between sunrise and sunset due to the warming of surface water by sunlight. Therefore, to improve the probability of favourable flight conditions, sampling is typically planned for early in the morning when wind speeds are likely to be low.

2. The sampling team establishes a 'safe flight area'. This is a $6 \mathrm{~m} \times 6 \mathrm{~m}$ area delineated with bright cones where the drone will take off and land. The 'safe flight area' must have an unobstructed, lineof-site view of the water surface and must be situated away from known hazards such as the tops of cliffs, the bottoms of highwalls, trees, powerlines, and active vehicle traffic. For safety purposes, no one is allowed inside the safe flight area when the drone is in operation without the pilot's permission.

3. The sample team places the Matrice 600 in the centre of the 'safe flight area', connects a $100 \mathrm{~m}$-long tether to the underside of the drone, and connects the CastAway-CTD to the opposite end of the tether. After a pre-flight safety check, the pilot raises the drone to an altitude of just over $100 \mathrm{~m}$ which raises the CTD off the ground. The pilot flies the drone to the coordinates above the deepest point in the water column, and then lowers the drone until the CTD rests on the bottom of the pit lake. This is indicated by slack in the tether line and the accumulation of line on the surface. Using binoculars, the spotter can easily identify when this has occurred. By design, the CastAway-CTD does not require extra time for temperature or conductivity measurements to stabilise; these parameters are measured instantaneously as water flows through the device during its decent and ascent. As such, there is no added benefit in allowing extra time for the device to stabilise at any given depth. If the maximum depth is $100 \mathrm{~m}$ or greater the pilot waits three minutes to allow the CTD to reach its maximum depth. The pilot then raises the drone and lands within the 'safe flight area'. The CTD rapidly uploads data to a laptop computer which promptly displays:

a. The maximum depth of the water column at the sample location.

b. In situ profiles of temperature, specific conductance and density.

4. These profiles illustrate depth ranges with uniform specific conductance (a proxy for TDS concentrations) which are interpreted as homogeneous layers and targeted for sampling.

5. The sample team exchanges the CTD with a water sampling device at the end of the $100 \mathrm{~m}$ tether, and connects a pressure transducer to the device. The pilot raises the drone and sampling device and returns the drone to the sample location. To collect a sample from the targeted depth, the pilot slowly lowers the drone until the sampling equipment touches the water surface. Using binoculars, the spotter confirms when this happens. The pilot then records the drone's altitude from the display on the control device. Next, the pilot lowers the altitude of the drone by a distance equal to the targeted sample depth. For example, if the targeted sample depth was $20 \mathrm{~m}$ and the initial altitude of the drone was $100 \mathrm{~m}$, the pilot would decrease the drone's altitude to $80 \mathrm{~m}$. The pilot collects the water sample and returns the sample device and aerial drone to the 'safe flight area'. The spotter fills sample bottles directly from the sampling device using standard sampling procedures. This step is repeated for each targeted sample depth.

6. After sampling, pressure transducer data are corrected for changes in barometric pressure. These data correct the sample depth to an accuracy of $\pm 10 \mathrm{~cm}$. 


\section{$4 \quad$ Case study 1: Montana Tunnels Pit Lake}

\subsection{Background}

On 23 October 2018, a three-person team from Golder Associates Inc. (Golder) measured in situ physiochemical parameters and collected three water samples from the Montana Tunnels Pit Lake near Jefferson City, Montana, USA (Figure 2). The pit lake occupies an inactive, polymetallic (i.e. zinc, lead, gold, and silver) open pit mine, which is now flooded. Table 1 shows some of the physical characteristics of the lake.

The mine was permitted in 1986, and operations began that same year. Since the start of operations, the Montana Department of Environmental Quality (MDEQ) required the routine collection of water samples from the pit sump (which varied in location, depth, and volume as the pit was developed). Mining operations and pit dewatering were suspended in 2008, pending the acquisition of funding to initiate an approved pit expansion. Thereafter, the water table rose and a pit lake developed.

The primary inflows to the pit lake included: (1) groundwater, (2) direct precipitation, and (3) runoff from the pit walls and the catchment area surrounding the pit. Sampling of the developing pit lake continued through 2010, with grab samples obtained from the water's edge. In 2011, a pit wall failure eliminated a large section of the access ramp, precluding further access to the lake by either vehicle or foot traffic. A more substantial failure in 2013 displaced a significant volume of highwall material into the pit lake. By 2018, the lake surface had risen to approximately 170 metres above the original pit floor elevation, but the actual depth of water was uncertain due to the accumulation of landslide debris beneath the surface. Public questions concerning the water chemistry within the growing pit lake could not be answered due to lack of access, leading MDEQ to investigate options for safely obtaining samples from the water body. Boat sampling was not an option, as surface access to the pit lake was not possible, either by vehicle or by foot, making access by air the only option.

This work was contracted by the MDEQ and was observed by representatives from MDEQ, the US Bureau of Land Management (BLM), and the Montana Tunnels Mining Company. Williams et al. (2018) described this sampling event in an 'Inspection Report,' copies of which can be requested from the Butte, Montana office of the BLM.

\subsection{Methods}

Under direction from MDEQ, Golder flew the aerial drone above a point on the water surface that was believed to overlie the deepest location within the pit lake. Flight 1 lowered a CastAway-CTD through the water column that recorded the maximum depth at this location $(70 \mathrm{~m})$ and measured in situ profiles of temperature and electrical conductivity. Temperature and specific conductance were uniform from the top to the bottom of the water column and indicated the lake had recently undergone complete mixing during autumn turnover (Figure 5). 

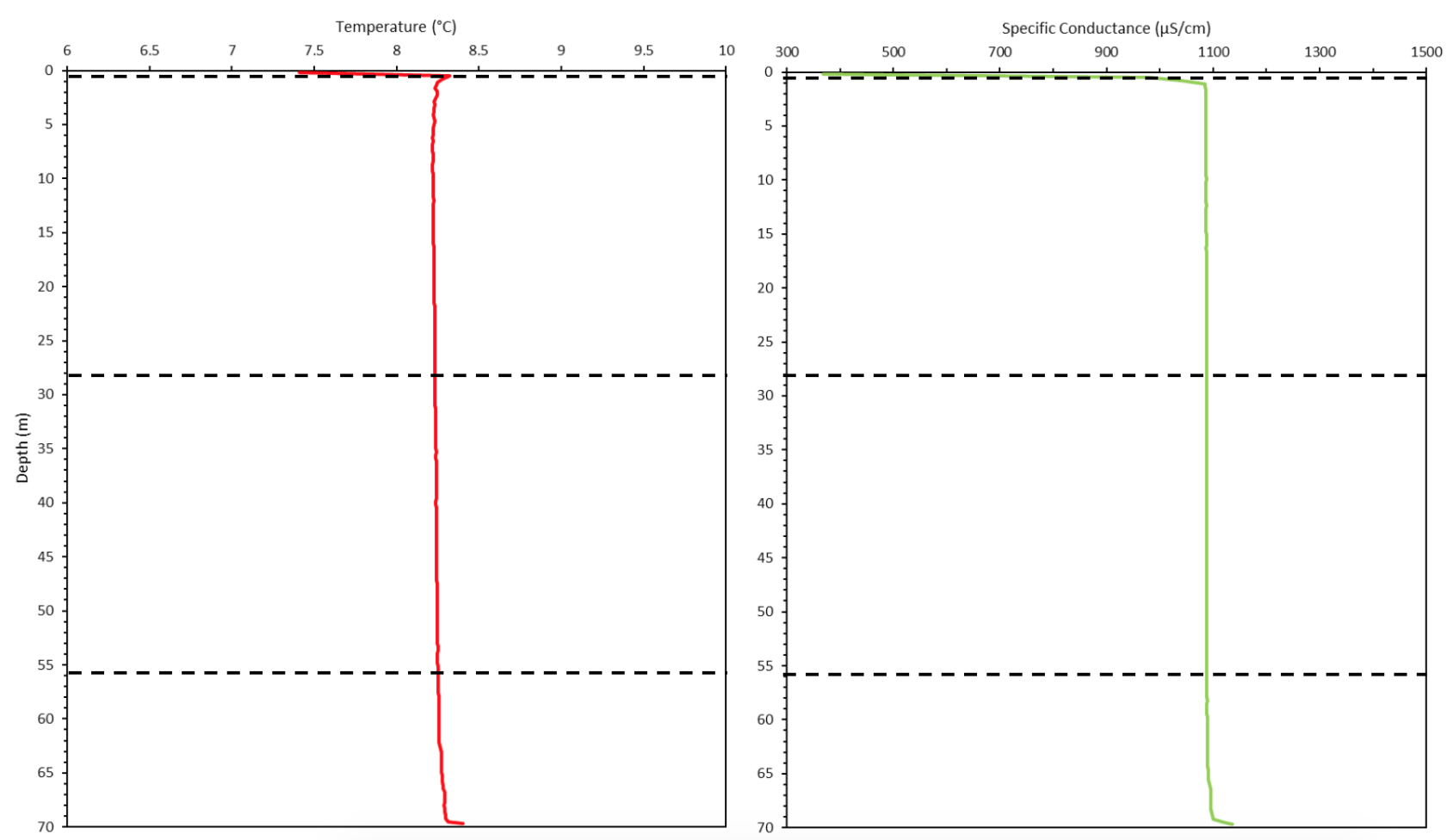

Figure 5 Temperature (left) and specific conductance (right) profiles from the Montana Tunnels Pit Lake on 23 October 2018. Horizontal dashed lines indicate corrected sample depths

\subsection{Results from in situ profiles}

The temperature profile showed a uniform water column temperature of approximately $8.2^{\circ} \mathrm{C}$, with slightly cooler water at the surface of the lake, and slightly warmer water at the lake bottom (Figure 5 ). This profile is characteristic of a lake which has recently mixed from top to bottom as a result of autumn turnover. Because the maximum density of water occurs at $4^{\circ} \mathrm{C}$, the water column was expected to continue to fully circulate until the entire water column achieves a temperature of $4^{\circ} \mathrm{C}$. Once the surface water drops below that temperature, winter stratification would develop. Cooler surface water may represent recent rainfall on the lake surface and/or radiant heat loss during the previous evening. Bottom temperatures probably reflect heat released from bottom sediments.

The specific conductance profile showed a uniform water column of approximately $1,087 \mu \mathrm{S} / \mathrm{cm}$, with a lower conductivity in the first $1.5 \mathrm{~m}$ of the water column $(300 \mu \mathrm{S} / \mathrm{cm})$ and slightly higher conductance at the lake floor $(1,135 \mu \mathrm{S} / \mathrm{cm})$ (Figure 5). Specific conductance indicated the relative concentration of TDS in lake water. The profiles in Figure 5 suggested that the chemistry of the lake was well mixed from top to bottom. As such, Golder expected that water samples collected from any depth would have a similar water quality. Lower values at the surface most likely indicated dilution by recent rainwater, whereas elevated values at the lake bottom possibly indicated higher TDS within the mud layer at the lake bottom.

\subsection{Sample depth selection and water chemistry}

Based on evidence of homogeneous conditions in the water column, Golder expected homogenous water quality throughout the lake. In this instance, one sample from the middle of the lake would have represented the water column. To ensure homogeneous conditions, three water samples were targeted based on a uniform sample spacing of $30 \mathrm{~m}$, at 0,30 , and $60 \mathrm{~m}$ depth. Flight 2 collected a $2 \mathrm{~L}$ water sample from the deepest depth. Flight 3 attempted to collect a sample from the immediate surface of the water, but upon return, the sample chamber contained only $0.6 \mathrm{~L}$. Flight 4 lowered the sampling device to three metres below the surface and returned with a $2 \mathrm{~L}$ sample. Flight 5 collected a $2 \mathrm{~L}$ sample from the mid-depth of the lake. Post processing of pressure transducer data showed the actual sample depths to have been 0,28 , and $56 \mathrm{~m}$ 
depths. All samples were collected within $4 \mathrm{~m}$ of the target sample depth, with the largest error occurring at the deepest sample depth. Analytical results from select parameters are shown in Table 3.

Table 3 Lab pH, dissolved major ions, total dissolved solids (TDS), and water density from the Montana Tunnels Pit Lake on 23 October 2018. Concentrations reported in mg/L. Density reported in $\mathrm{kg} / \mathrm{m}^{3}$

\begin{tabular}{llllllllll}
\hline Depth & $\mathbf{p H}$ & $\mathrm{Ca}^{2+}$ & $\mathbf{M g}^{2+}$ & $\mathbf{N a}^{+}$ & $\mathbf{C l}^{-}$ & $\mathbf{H C}^{03-}$ & SO$^{42-}$ & TDS & Density \\
\hline $0 \mathrm{~m}$ & 8.0 & 138 & 49 & 18 & 1 & 210 & 376 & 790 & $1,000.02$ \\
$28 \mathrm{~m}$ & 8.0 & 140 & 50 & 18 & 2 & 210 & 374 & 794 & $1,000.39$ \\
$56 \mathrm{~m}$ & 7.9 & 139 & 49 & 18 & 1 & 200 & 386 & 790 & $1,000.52$ \\
\hline
\end{tabular}

\subsection{Summary}

The Montana Tunnels Pit Lake exhibited a well-mixed profile at the time of sampling. As predicted by in situ profiles, analytical results showed little variability in water chemistry across the upper $56 \mathrm{~m}$ of the water column (Table 3).

Both state (MDEQ) and federal (US BLM) regulators approved the drone water sampling methods and accepted the three water samples for regulatory compliance purposes. Given that the MDEQ originally requested only two water samples from 3 and $15 \mathrm{~m}$ deep, the methods provided added value with one additional sample and greater vertical characterisation of the water column. Most importantly, the use of aerial drone water sampling allowed for sampling of a pit lake that is only accessible by air.

\section{$5 \quad$ Case study 2: Thompson Creek Pit Lake}

\subsection{Background}

Three weeks after sampling the Montana Tunnels Pit Lake, on 13 November 2018, a two-person drone sampling team from Golder measured in situ physiochemical parameters and collected eight water samples from the Thompson Creek Mine Pit Lake near Clayton, Idaho, USA (Figure 2). The Thompson Creek Pit Lake is $295 \mathrm{~km}$ southeast of the Montana Tunnels Pit Lake and has several similar attributes (Table 1).

Active mining at Thompson Creek open pit mine ceased in December of 2014 due to sustained depression of molybdenum trioxide prices. During active mining, pumps were utilised to control groundwater infiltration and dewater the mine pit. A temporary pit lake has since developed within the Thompson Creek Mine pit as a result of this extended Care and Maintenance period.

If full-scale closure of the mine is implemented, this existing water body will become a permanent feature which will be utilised for long-term water management throughout closure and post-closure when continuous discharge to the environment will be necessary. Alternatively, if open pit mining is restarted, the pit lake will require dewatering at a meaningful rate. Dewatering the pit at such a rate assumes discharge to the environment will be necessary.

Regardless of cause for this action, the discharge stream will require some level of treatment to ensure that it meets applicable effluent limits. Predictive water quality models have been developed based on empirically-derived geochemical data to conservatively estimate the in-pit concentrations for comparison to the effluent limits for the purposes of determining the level of treatment necessary to allow discharge. The selection, sizing and cost of the treatment technology has been based upon the predictive models developed for this site. According to the predictive models, the pit lake will develop stratification and unfavourable water quality throughout the water column, although the timing of this occurrence and extent is uncertain. Therefore, regardless of whether the discharges are necessary to facilitate dewatering in advance of mine 
restart or long-term water management (i.e. treatment) it is critical to monitor the rate of change for in-pit water quality.

The Thompson Creek Pit Lake occupies a portion of the open pit and is therefore in contact with the ore bearing zone as well as relatively inert overburden. Landslides, which were actively managed and mitigated when the pit was in operation, have frequently occurred from pit walls into the pit lake. These have raised safety concerns about routinely accessing the pit lake for sampling or other purposes. The most significant landslide occurred in December of 2016 which produced a large tsunami and resulted in a substantial loss of equipment. This event exacerbated already heightened safety concerns regarding placing personnel in boats on the pit lake given that the first boat-based pit water quality sampling event concluded less than a month prior to this landslide. No repeat boat-based sampling event was attempted or planned since.

The primary inflows to the pit lake include:

- Water pumped from the tailings pond.

- Groundwater.

- Direct precipitation.

- Seepage water from the waste rock storage facilities.

- Runoff from the pit walls and the catchment area surrounding the pit.

The mine routinely adds lime to the inflows which are pumped to the pit. There is no surface outlet from the lake.

\subsection{Methods}

Under direction of mine staff, Golder made 10 flights to a point on the water surface that was believed to overlie the deepest location within the pit lake. Flights 1 and 8 were used to lower a CastAway-CTD to the base of the water column. Flight 1 measured a maximum depth of $66 \mathrm{~m}$ whereas Flight 8 , conducted five hours later, measured a maximum depth of $92 \mathrm{~m}$. We believe that not enough time was allowed for the CTD to sink to the lake floor during Flight 1 which prompted Flight 8 to the same location. Flights 2 through 7, 9, and 10 collected $2 \mathrm{~L}$ water samples from targeted depths.

\subsection{Results from in situ profiles}

Two in situ profiles of temperature and specific conductance were collected five hours apart during Flights 1 $(66 \mathrm{~m})$ and $8(92 \mathrm{~m})$ (Figure 6). The close similarity between each profile indicates consistency in the profiling method and that little change occurred within the water column during water sampling. 

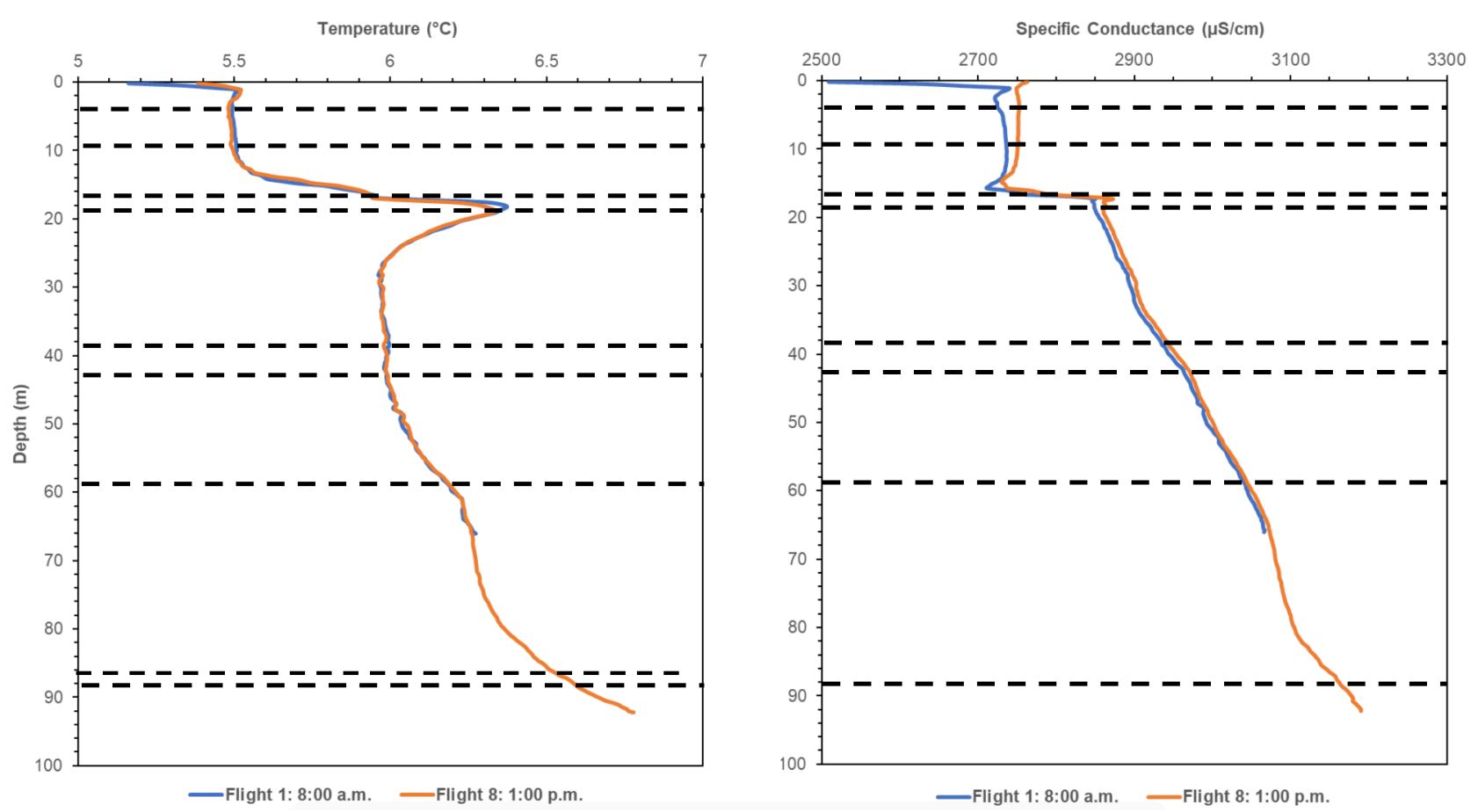

Figure 6 Temperature (left) and specific conductance (right) profiles from the Thompson Creek Pit Lake on 13 November 2018. Horizontal dashed lines indicate corrected sample depths

Temperature and electrical conductivity indicated the presence of a shallow layer from 0 to $13 \mathrm{~m}$, a transitional boundary from 13 to $26 \mathrm{~m}$, and a deep layer from $26 \mathrm{~m}$ to $92 \mathrm{~m}$ (Figure 6). Uniform temperature and specific conductivity profiles in the shallow layer, above $13 \mathrm{~m}$ depth, indicate that the layer was well mixed above this depth at the time of sampling. Mixing is driven by wind acting on the water surface. The coldest temperatures in the lake $\left(5.2^{\circ} \mathrm{C}\right)$ occurred at the surface of the lake which indicates radiant heat loss during the previous evening.

Between 13 to $26 \mathrm{~m}$ depth, temperature increases by about $1^{\circ} \mathrm{C}$ to $6.4^{\circ} \mathrm{C}$ (Figure 6). At the same depth, specific conductance slightly increased by $200 \mu \mathrm{S} / \mathrm{cm}$ to $2,900 \mu \mathrm{S} / \mathrm{cm}$. This may indicate the presence of tailings pond water pumped into the lake or groundwater entering the lake. In both cases, the influent water most likely has a different temperature, TDS concentration, and density than the ambient lake water. This density difference causes the influent to rise or fall through the water column until it arrives at a depth of neutral buoyancy, in this case $18 \mathrm{~m}$ depth. This was a unique layer targeted by the $17 \mathrm{~m}$ sample.

Below the transitional boundary, temperature and specific conductance increase to the lake bottom (Figure 6). The temperature increases of $0.5^{\circ} \mathrm{C}$ may be due to heat released from pit walls and/or bottom sediment, or the addition of groundwater $\left(\sim 11^{\circ} \mathrm{C}\right)$. The specific conductance increase of $200 \mu \mathrm{S} / \mathrm{cm}$ may be due to groundwater inflow, tailings pond water, and/or the downward settling of suspended particulate matter (i.e. mineral precipitates) from the surface.

\subsection{Sample depth selection}

Based on the variability within the water column, Golder recommended collecting two water samples from the shallow layer at 0 and $10 \mathrm{~m}$, one water sample from the transitional boundary at $17 \mathrm{~m}$, and four samples from the deep layer at 20,40,60, and $90 \mathrm{~m}$. An eighth, duplicate sample was collected from the middle of the water column at $40 \mathrm{~m}$ depth.

The pressure transducer data corrected the field depths to $3,8,15,17,36,40,55$, and $83 \mathrm{~m}$. All samples were collected within $7 \mathrm{~m}$ of the target sample depth, with the largest error occurring at the deepest sample depth. Samples from 3, 15, 40, and $83 \mathrm{~m}$ depths were submitted for laboratory analysis. Analytical results from select parameters are shown in Table 4. 
Table 4 Lab $\mathrm{pH}$, dissolved major cations, total sulphide ( $\left.\mathrm{S}^{-}\right)$, total organic carbon (TOC), total dissolved solids (TDS), and water density from the Thompson Creek Pit Lake on 13 November 2018. Concentrations reported in $\mathrm{mg} / \mathrm{L}$. Density reported in $\mathrm{kg} / \mathrm{m}^{3}$

\begin{tabular}{lccccccccc}
\hline Depth & $\mathbf{p H}$ & $\mathbf{C a}^{2+}$ & $\mathbf{M g}^{2+}$ & $\mathbf{N a}^{+}$ & $\mathbf{K}^{+}$ & $\mathbf{S}^{-}$ & TOC & TDS & Density \\
\hline $3 \mathrm{~m}$ & 7.6 & 406 & 28 & 199 & 12 & $<0.04$ & 0.9 & 2,220 & $1,001.08$ \\
$15 \mathrm{~m}$ & 7.6 & 401 & 29 & 204 & 12 & $<0.04$ & 1.1 & 2,230 & $1,001.12$ \\
$40 \mathrm{~m}$ & 7.2 & 429 & 27 & 225 & 12 & $<0.04$ & 0.9 & 2,400 & $1,001.33$ \\
$83 \mathrm{~m}$ & 7.2 & 464 & 26 & 236 & 11 & $<0.04$ & 0.9 & 2,570 & $1,001.60$ \\
\hline
\end{tabular}

\subsection{Summary}

The Thompson Creek Pit Lake exhibited a stratified water column with two distinct layers separated by a transitional boundary between 13 and $26 \mathrm{~m}$ deep. Judging from the calendar date and the observation of turnover in the Montana Tunnels Pit Lake, sampling occurred at the end of the summer stratification period and the start of autumn turnover. Golder collected eight water samples from multiple depths in the water column in order to capture variability in water quality with depth.

In situ profiles could not resolve whether the pit lake exhibited holomictic or meromictic conditions at the time of sampling. However, with the assistance of geochemical results, the following lines of evidence suggested the lake was holomictic:

- Specific conductance (Figure 6), pH, and major cations and TDS concentrations (Table 4) show only minor changes between the shallow and deep layers. This is typical of a holomictic lake. The deep layer of meromictic lakes typically exhibits significantly higher TDS than the shallow layer and may also have a slightly higher $\mathrm{pH}$.

- The deep layer exhibited little to no sulphide concentrations. This is typical of a holomictic lake. The deep layer of meromictic lakes typically exhibits anoxic conditions where sulphide is generated as a product of sulphate reduction.

Golder predicted the following changes would occur in the weeks following the sampling event. The density of the surface layer would continue to increase as the surface layer cooled from 5.2 to $4.0^{\circ} \mathrm{C}$, with $4.0^{\circ} \mathrm{C}$ corresponding to the maximum density of freshwater. As the density of the surface layer increased, surfacelayer-mixing would deepen. If the lake is holomictic, the density of the surface layer will ultimately exceed the density of the underlying water column, and the entire lake would circulate from top to bottom. This event would be called 'complete autumn turnover'. If complete turnover occurred, it would homogenise the temperature and specific conductance profiles, eliminating the temperature spike at $18 \mathrm{~m}$ as well as the gradual increase in temperature and specific conductance in the deep layer. The resulting profile would look similar to Figure 5 only with higher specific conductance.

After the temperature of the surface layer drops below $4^{\circ} \mathrm{C}$, the lake will enter a period of 'winter stratification'. In this period, a colder (i.e. $0^{\circ} \mathrm{C}$ ), less-dense, surface layer would overly a slightly warmer (i.e. $4^{\circ} \mathrm{C}$ ), more-dense, deep layer. Ice will ultimately develop on the lake surface, removing the supply of oxygen to lake water until ice-off occurs in the spring of 2019. 


\section{Discussion and conclusion}

Aerial drones decrease risks associated with pit lake water sampling by eliminating the need to work on water or access a pit. Prior to aerial drone water sampling, in situ profiles are collected, allowing for:

- Identification of unique layers worthy of investigation (e.g. the 17 m-deep sample in Thompson Creek Pit Lake, Figure 6).

- Interpretation of the physical state of the lake with respect to seasonal stratification or mixing.

- Justification for a minimum number of samples for geochemical characterisation.

- Selection of sample depths within individual layers.

By comparison, collecting water samples using a fixed-depth-interval and no prior knowledge of stratification may lead to more sampling than necessary for characterisation, higher costs, and missing samples from chemically unique layers.

Two pit lakes located in the same geographic region of the United States with similar elevations and similar maximum depths were sampled with an aerial drone. Sampling occurred three weeks apart in the autumn of 2018. Based on these characteristics, the authors hypothesised that both lakes might be fully mixed as a product of autumn turnover. However, in situ profiles showed the Montana Tunnels Pit Lake to be fully mixed (Figure 5) whereas the Thompson Creek Pit Lake still exhibited summer stratification despite being at a slightly higher altitude and having colder water temperatures (Figure 6). Several factors may have contributed to these differences in physical stratification, including:

- Differences in local weather conditions, such as wind speed.

- Differences in the quantity, quality and depth of lake inflows (i.e. the Thompson Creek Pit Lake receives lime-treated, tailings pond water and seepage from a waste rock storage facility whereas the Montana Tunnels Pit Lake does not).

- Differences in the vertical density gradient. The water column of the Thompson Creek Pit Lake exhibited an increase in water density between 16 and $17 \mathrm{~m}$ depth as reflected by changes in temperature and specific conductance (Figure 6). This density gradient provided resistance to vertical mixing at the time of sampling. Presumably, the Montana Tunnels Pit Lake exhibited a smaller vertical density gradient prior to sampling which allowed it to mix prior to sampling. The water column of the Thompson Creek Pit Lake is roughly $1 \mathrm{~kg} / \mathrm{m}^{3}$ denser than the water column of the Montana Tunnels Pit Lake (Tables 3 and 4).

Differences in vertical stratification in lakes with similar characteristics highlights the need for individual, sitespecific sampling plans developed from direct observations. As a result, samples were collected from different depths in each pit lake with more samples collected from the Thompson Creek Pit Lake due to its vertical variability. Geochemical results confirmed the presence of homogeneous layers previously identified from in situ profiles and indicated that both lakes should be holomictic.

By eliminating the need for humans to access the pit lake water surface, aerial drones have been shown to provide a safe method to collect water samples from inaccessible and hazardous pit lakes. For the Montana Tunnels Pit Lake, the water surface was inaccessible to foot or vehicle traffic due to past pit wall failures. For the Thompson Creek Pit Lake, the risk of future pit wall failures created a high health and safety risk to boatbase personnel. At both pit lakes, in situ profiles of temperature and electrical conductivity collected by drones prior to water sampling allowed the field team to select the most appropriate depths for water sample collection based on the vertical structure of the water column. The Montana Tunnels Pit Lake was fully mixed at the time of sampling and required a minimum number of samples (i.e. $n=3$ ) to characterise the water column, whereas the Thompson Creek Pit Lake exhibited summer stratification and required a larger number (i.e. $n=8$ ) of samples to characterise vertical variability in water quality. As such, drones provided a rapid approach to develop a site-specific sampling plan appropriate for the day of sampling that improved the efficiency of sampling efforts. 


\section{Acknowledgement}

Golder thanks the Montana Department of Environmental Quality, Montana Tunnels Mining Company, and the Thompson Creek Mining Company for permission to publish these data.

\section{References}

Castendyk, D \& Eary, TE (eds) 2009, 'Mine Pit Lakes: Characteristics, Predictive Modeling, and Sustainability', Society for Mining, Metallurgy, and Exploration, Littleton, Colorado, $304 \mathrm{p}$.

Castendyk, D, Hill, B, Filiatreault, P, Straight, B, Alangari, A, Cote, P \& Leishman, W 2018, 'Experiences with autonomous sampling of pit lakes in North America using drone aircraft and drone boats,' in C Wolkersdoffer, L Sartz, A Weber, J Burgess \& G Tremblay (eds), Proceedings of the 11th International Conference on Acid Rock Drainage \& International Mine Water Association 2018 Annual Conference, International Network for Acid Prevention, Pretoria, South Africa, pp. 1036-1041.

Castendyk, D, Straight, B, Filiatreault, P, Thibeault, S \& Cameron, L 2017, 'Aerial drones used to sample pit lake water quality reduce costs and improve safety', Mining Engineering, vol. 69, no. 7, pp. 20-28.

Cornell, D, Herman, M \& Ontiveros, F 2016, 'Use of a UAV for water sampling to assist remote sensing of bacterial flora in freshwater environments,' Undergraduate External Publications, paper 17, St. John Fisher College, Rochester, New York, viewed 1 April, 2019, http://fisherpub.sjfc.edu/undergraduate_ext_pub/17

Geller, W, Schultze, M, Kleinmann, B \& Wolkersdorfer, C (eds) 2013, Acidic pit lakes; the legacy of coal and metal surface mines, Springer-Verlag, Berlin.

IRYS Pty Ltd 2016, 'Tallering Peak, mid-west Western Australia,' YouTube video, IRYS Pty Ltd, viewed 1 April 2019, https://www.youtube.com/watch?v=rx4nmuieLDM

Koparan, C, Koc, AB, Privette, CV, Sawyer, CB \& Sharp, JL 2018, 'Evaluation of a UAV-assisted autonomous water sampling,' Water, vol. 10 , no. $655,16 \mathrm{p}$.

McCullough, CD (ed.) 2011, Mine Pit Lakes: Closure and Management, Australian Centre for Geomechanics, Perth, Western Australia.

Newman, CP, Castendyk, D, Straight, B, Filiatreault, P \& Pino, A 2018, 'Remote water-quality sampling of Nevada pit lakes using unmanned aircraft systems,' Geological Society of America, Abstracts with Programs, vol. 50, no. 5.

Ore, JP, Elbaum, S, Burgin, A \& Detweiler, C 2015, 'Autonomous aerial water sampling,' Journal of Field Robotics, vol. 32, no. 8, pp. 1095-1113.

Schultze, M, Boehrer, B, Wendt-Potthoff, K, Sánchez-España, J \& Castendyk, D 2017, 'Meromictic pit lakes: case studies from Spain, Germany and Canada and general aspects of management and modelling', in RD Gulati, E Zadereev \& AG Degermendzhi (eds), Ecology of Meromictic Lakes, Ecological Studies 228, Springer International Publishing.

Terada, A, Morita, Y, Hashimoto, T, Mori, T, Ohba, T, Yagauchi, M \& Kanda, W 2018, 'Water sampling using a drone at Yugama crater lake, Kusatsu-Shirane volcano, Japan,' Planets and Space, vol. 70, no. 64, 9 p.

Washburn, L, Romero, E, Salazar, D, Valdez-Schulz, A, Welch, Z \& Iglesias-Rodriguez, D 2018, 'Water sampling from aerial drones for water quality research in coastal and inland waters', 2018 Ocean Sciences Meeting, Association for the Sciences of Limnology and Oceanography, Portland, Oregon, Poster CD14A-0023.

Wetzel, RG 2001, Limnology; Lake and River Ecosystems, 3rd Edition, Academic Press, San Diego.

Williams, D, Haight, S, Jepson, W, Smith, G, Walsh, D, Mohrmann, J, Danesi, D \& Bell, C 2018, 'Surface management inspection, Montana Tunnels Pit Lake, Jefferson City, Montana, U.S. BLM Inspection Report 3809, Butte, Montana, 23 October 2018. 